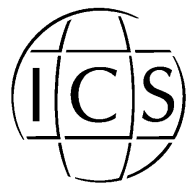

www.ics-elsevier.com

\title{
POP-Gene TIMOR: first forensic DNA marker study of East-Timor people
}

\author{
L. Souto $^{a, *}$, L. Gusmão ${ }^{b}$, A. Amorim ${ }^{\text {b,c }}$, E. Ferreira ${ }^{a}$, \\ F. Côrte-Real ${ }^{\text {d,e }}$, D.N. Vieira ${ }^{\text {d,e }}$, E.F. da Cruz e Silva ${ }^{a}$ \\ ${ }^{a}$ Centro de Biologia Celular, Departamento de Biologia, Universidade de Aveiro, Aveiro, Portugal \\ ${ }^{\mathrm{b}}$ Instituto de Patologia e Imunologia Molecular da Universidade do Porto, Portugal \\ ${ }^{\mathrm{c}}$ Faculdade de Ciências, Universidade do Porto, Portugal \\ d Delegação de Coimbra, Instituto Nacional de Medicina Legal, Coimbra, Portugal \\ ${ }^{\mathrm{e}}$ Faculdade de Medicina da Universidade de Coimbra, Portugal
}

\begin{abstract}
The first population-genetics study for the world newest independent country, East Timor, is presented. In this preliminary work, part of a major ongoing study on East-Timor genetic diversity, the allele frequencies and some statistical parameters of forensic interest were determined for the 15 loci included in AmpFLSTR Identifiler ${ }^{\mathrm{TM}}$ genotyping kit. A total of 107 samples, collected from East Timorese of several linguistic groups, was typed. All markers are in Hardy-Weinberg equilibrium (except for D2S1338 and D5S818, but the deviations do not reach significance after Bonferroni correction). Observed heterozigosities varied between 72\% (D5S818) and 92\% (D8S1179). (C) 2003 Elsevier B.V. All rights reserved.
\end{abstract}

Keywords: STR; East Timor; Identifiler; Population genetics

\section{Introduction}

East Timor, a Portuguese colony from the 16th century until Indonesian occupation in 1975, gained finally its independence, after a tragic and complex political process on May 20th, 2002. East Timor is indeed a complex multilingual mosaic and its ethnic and linguistic heterogeneity has long attracted scientific interest in areas such as anthropology, linguistics and archaeology and constitutes a challenge to human genetics.

The AmpFLSTR ${ }^{\circledR}$ Identifiler $^{\mathrm{TM}}$ PCR Amplification Kit (Applied Biosystems) is being widely used in forensics (as well as in paternity studies), as it complies with international standards and recommendations such as those from the Combined DNA Index System (CODIS), the European Network of Forensic Science Institutes (ENFSI) and Interpol. We present preliminary data from the first (to our knowledge) DNA study concerning East-Timorese populations, as part of a broad ongoing study of East-Timor

\footnotetext{
* Corresponding author. Tel.: +351-234-370783; fax: +351-234-426408.
}

E-mail address: 1souto@bio.ua.pt (L. Souto). 
Allele frequencies and statistical parameters of forensic relevance, for the 15 Identifiler ${ }^{\mathrm{TM}}$ STRs in East-Timor population

\begin{tabular}{|c|c|c|c|c|c|c|c|c|c|c|c|c|c|c|c|}
\hline & D8S1179 & D21S11 & D7S820 & CSF1PO & D3S1358 & HUMTH01 & D13S317 & D16S539 & D2S1338 & D19S433 & HUMVWA & TPOX & D18S51 & D5S818 & FGA \\
\hline 6 & & & & & & 0.098 & & & & & & 0.005 & & & \\
\hline 7 & & & 0.009 & & & 0.159 & & & & & & & & & \\
\hline 8 & 0.005 & & 0.257 & 0.005 & & 0.350 & 0.299 & 0.028 & & & & 0.332 & & & \\
\hline 9 & & & 0.028 & 0.061 & & 0.341 & 0.075 & 0.154 & & & & 0.308 & & 0.023 & \\
\hline 9.3 & & & & & & 0.009 & & & & & & & & & \\
\hline 10 & 0.042 & & 0.229 & 0.210 & & 0.042 & 0.112 & 0.210 & & & & 0.028 & & 0.318 & \\
\hline 11 & 0.126 & & 0.285 & 0.332 & & & 0.248 & 0.318 & & & & 0.299 & 0.005 & 0.229 & \\
\hline 12 & 0.112 & & 0.168 & 0.290 & 0.005 & & 0.201 & 0.182 & & 0.047 & & 0.028 & 0.037 & 0.290 & \\
\hline 13 & 0.201 & & 0.019 & 0.093 & 0.005 & & 0.051 & 0.093 & & 0.308 & & & 0.079 & 0.136 & \\
\hline 13.2 & & & & & & & & & & 0.023 & & & & & \\
\hline 14 & 0.234 & & 0.005 & 0.009 & 0.009 & & 0.014 & 0.009 & & 0.243 & 0.117 & & 0.196 & 0.005 & \\
\hline 14.2 & & & & & & & & & & 0.075 & & & 0.005 & & \\
\hline 15 & 0.112 & & & & 0.336 & & & 0.005 & & 0.056 & 0.084 & & 0.145 & & \\
\hline 15.2 & & & & & & & & & & 0.182 & & & & & \\
\hline 16 & 0.098 & & & & 0.322 & & & & & 0.033 & 0.173 & & 0.150 & & \\
\hline 16.2 & & & & & & & & & & 0.028 & & & & & \\
\hline 17 & 0.065 & & & & 0.266 & & & & 0.089 & 0.005 & 0.243 & & 0.178 & & \\
\hline 18 & 0.005 & & & & 0.051 & & & & 0.042 & & 0.257 & & 0.070 & & 0.005 \\
\hline 19 & & & & & 0.005 & & & & 0.215 & & 0.117 & & 0.056 & & 0.089 \\
\hline 20 & & & & & & & & & 0.042 & & 0.009 & & 0.019 & & 0.051 \\
\hline 21 & & & & & & & & & 0.028 & & & & 0.028 & & 0.117 \\
\hline 22 & & & & & & & & & 0.107 & & & & 0.019 & & 0.206 \\
\hline 23 & & & & & & & & & 0.206 & & & & 0.005 & & 0.206 \\
\hline 24 & & & & & & & & & 0.192 & & & & & & 0.154 \\
\hline 25 & & & & & & & & & 0.070 & & & & 0.005 & & 0.093 \\
\hline 26 & & & & & & & & & 0.005 & & & & 0.005 & & 0.047 \\
\hline 27 & & 0.005 & & & & & & & 0.005 & & & & & & 0.028 \\
\hline 28 & & 0.112 & & & & & & & & & & & & & 0.005 \\
\hline 29 & & 0.262 & & & & & & & & & & & & & \\
\hline 30 & & 0.196 & & & & & & & & & & & & & \\
\hline 30.2 & & 0.005 & & & & & & & & & & & & & \\
\hline 31 & & 0.103 & & & & & & & & & & & & & \\
\hline 31.2 & & 0.103 & & & & & & & & & & & & & \\
\hline 32 & & 0.019 & & & & & & & & & & & & & \\
\hline 32.2 & & 0.154 & & & & & & & & & & & & & \\
\hline 33 & & 0.005 & & & & & & & & & & & & & \\
\hline 33.2 & & 0.028 & & & & & & & & & & & & & \\
\hline 35.2 & & 0.005 & & & & & & & & & & & & & \\
\hline 37.2 & & 0.005 & & & & & & & & & & & & & \\
\hline $\mathrm{H}$ obs. & 0.91589 & 0.84112 & 0.80374 & 0.76636 & 0.74766 & 0.74766 & 0.82243 & 0.79439 & 0.76636 & 0.85981 & 0.84112 & 0.77570 & 0.86916 & 0.71963 & 0.90654 \\
\hline H exp. & 0.85222 & 0.83818 & 0.77434 & 0.75275 & 0.71541 & 0.72748 & 0.79154 & 0.79356 & 0.85007 & 0.80628 & 0.81436 & 0.70708 & 0.87333 & 0.74722 & 0.85977 \\
\hline$P$ & 0.25516 & 0.53635 & 0.20094 & 0.69158 & 0.36875 & 0.26378 & 0.79872 & 0.75580 & 0.02591 & 0.80129 & 0.14264 & 0.20487 & 0.46464 & 0.01221 & 0.36966 \\
\hline
\end{tabular}

obs.: Observed Heterozygosity; $\mathrm{H}$ exp.: Expected Heterozygosity.

$P$ : Hardy-Weinberg equilibrium $P$ value, exact test based on more than 2000 shuffling, for standard error $<0.01$. 
Genetics (POP-Gene TIMOR), which involves the cooperative efforts of the Ministry of Health of the República Democrática de Timor-Leste (RDTL) and Portuguese institutions.

\section{Materials and methods}

Blood/saliva samples, in FTA $^{\mathrm{TM}}$ cards, were collected from 107 unrelated donors (with informed consent), belonging to different geographic (and linguistic) origins in East Timor. The DNA was extracted using the Chelex procedure [1] over a $3-\mathrm{mm}^{2}$ cut of the $F T A^{\mathrm{TM}}$ card.

Amplification of the 15 STR Identifiler ${ }^{\mathrm{TM}}$ loci (CSF1P0, D2S1338, D3S1358, D5S818, D7S820, D8S1179, D13S317, D16S539, D18S51, D19S433, D21S11, FGA, TH01, TPOX, VWA), plus the gender marker Amelogenin, was performed following the manufacturer's recommendations.

Amplified fragments were separated using an ABI 310 Automated Sequencer and analysed with GeneScan Software. All "off-ladder" fragments were typed at least twice. The population-genetics analyses were performed using the Arlequin software package [2].

\section{Results and discussion}

Allele frequencies (and relevant forensic statistical parameters) for the East-Timor subjects studied are shown in Table 1 for the 15 Identifiler $^{\mathrm{TM}}$ STRs. No deviations from $\mathrm{H}-\mathrm{W}$ equilibrium were observed with the exception of D2S1338 and D5S818 loci, but the deviations do not reach significance after Bonnferroni correction. The observed heterozigosities varied between 72\% (D5S818) and 92\% (D8S1179) and the observed average heterozygosity $(81 \%)$ is not significantly different from the expected value $(79 \%)$.

\section{Acknowledgements}

The authors would like to thank the former CATTL, Comissariado para a Transição em Timor-Leste, the Social Services of the University of Aveiro, Portugal, and the Health Services of the former Portuguese Mission in East Timor for their support. A special thanks to the East-Timorese volunteers for their contribution and empathy.

This work was partially supported by Programa Operacional Ciência, Tecnologia e Inovação (POCTI), Quadro Comunitário de Apoio III.

\section{References}

[1] P.S. Walsh, D.A. Metzer, R. Higuchi, Chelex-100 as a medium for simple extraction of DNA for PCR-based typing from forensic material, BioTechniques 10 (1991) 506-513.

[2] S. Schneider, D. Roessli, L. Excoffier, Arlequin: A Software for Population Genetics Data Analysis. Ver 2.000, Genetics and Biometry Lab., Dept. of Anthropology, University of Geneva, Geneva, 2000. 